\title{
Probing the Surface Curie Temperature of Ferroelectric P(VDF-ran-TrFE) Copolymers by Argon Gas Cluster Ion Scattering
}

\author{
$\underline{\text { Mykhailo CHUNDAK }^{1 *}}$, Claude POLEUNIS ${ }^{1}$, Vincent DELMEZ ${ }^{1}$, Alain M. JONAS ${ }^{1}$, Arnaud \\ DELCORTE ${ }^{1}$
}

${ }^{1}$ Institute of Condensed Matter and Nanosciences (IMCN), Université catholique de Louvain (UCL),

Place Louis Pasteur 1, box L4.01.10 B-1348, Louvain-la-Neuve, Belgium

Arnaud.delcorte@uclouvain.be

Supplementary Information

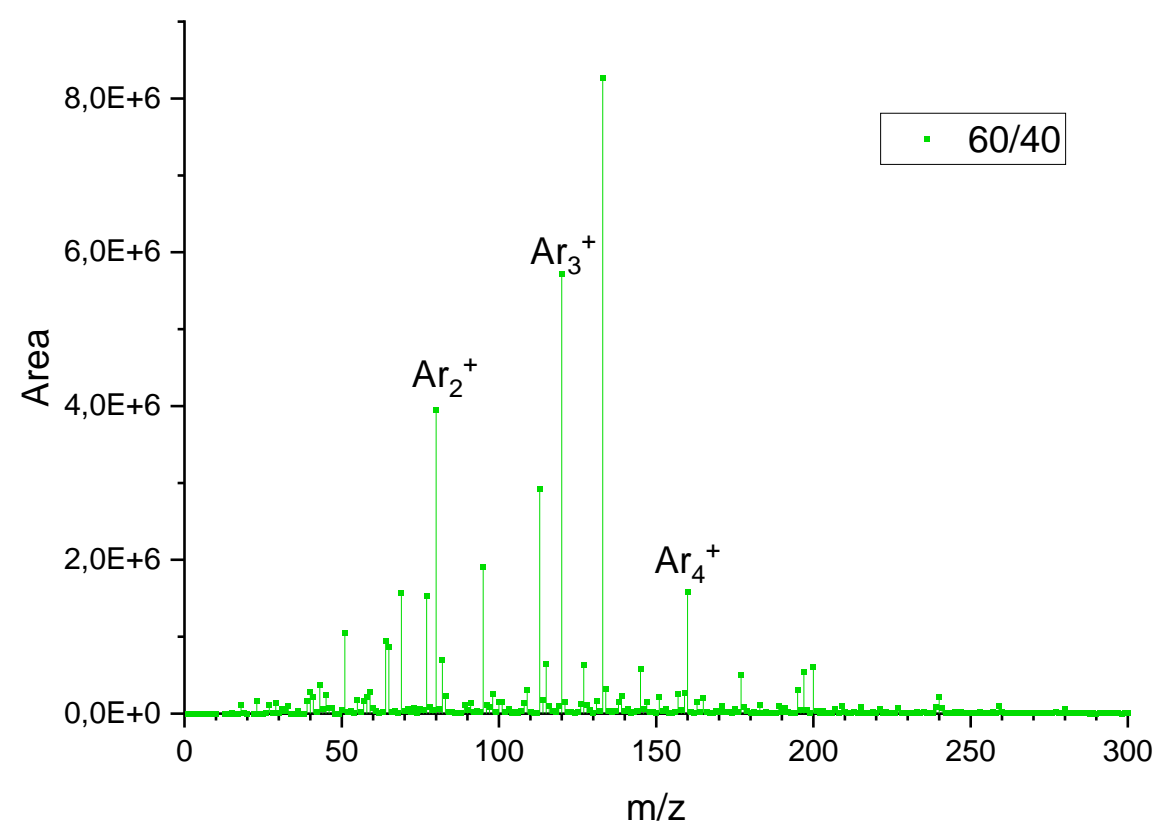



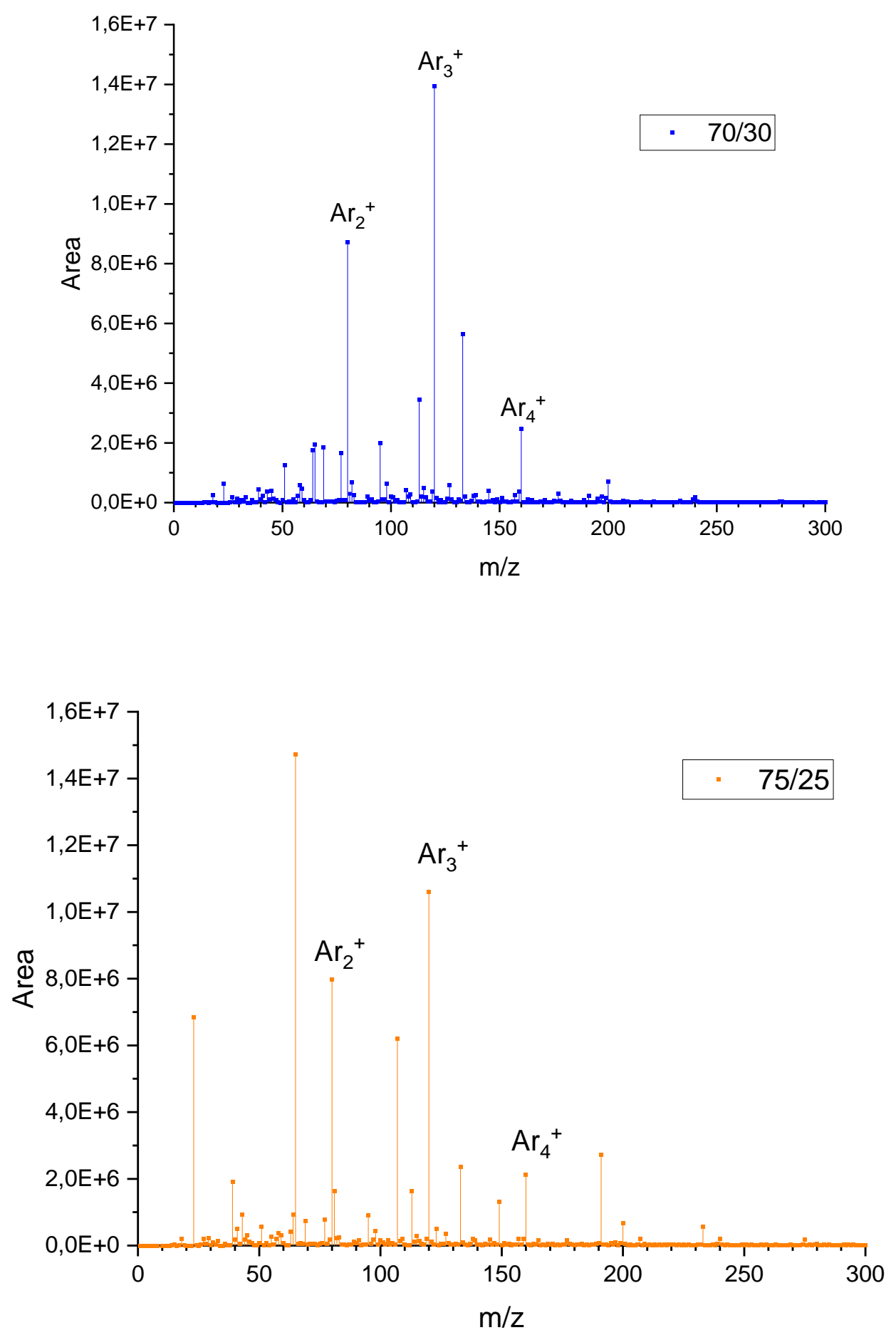

Figure S1 ToF SIMS spectra of the P(VDF-ran-TrFE) 60/40, 70/30, 75/25 thin films with marked $\mathrm{Ar}_{\mathrm{n}}{ }^{+}$peaks. 

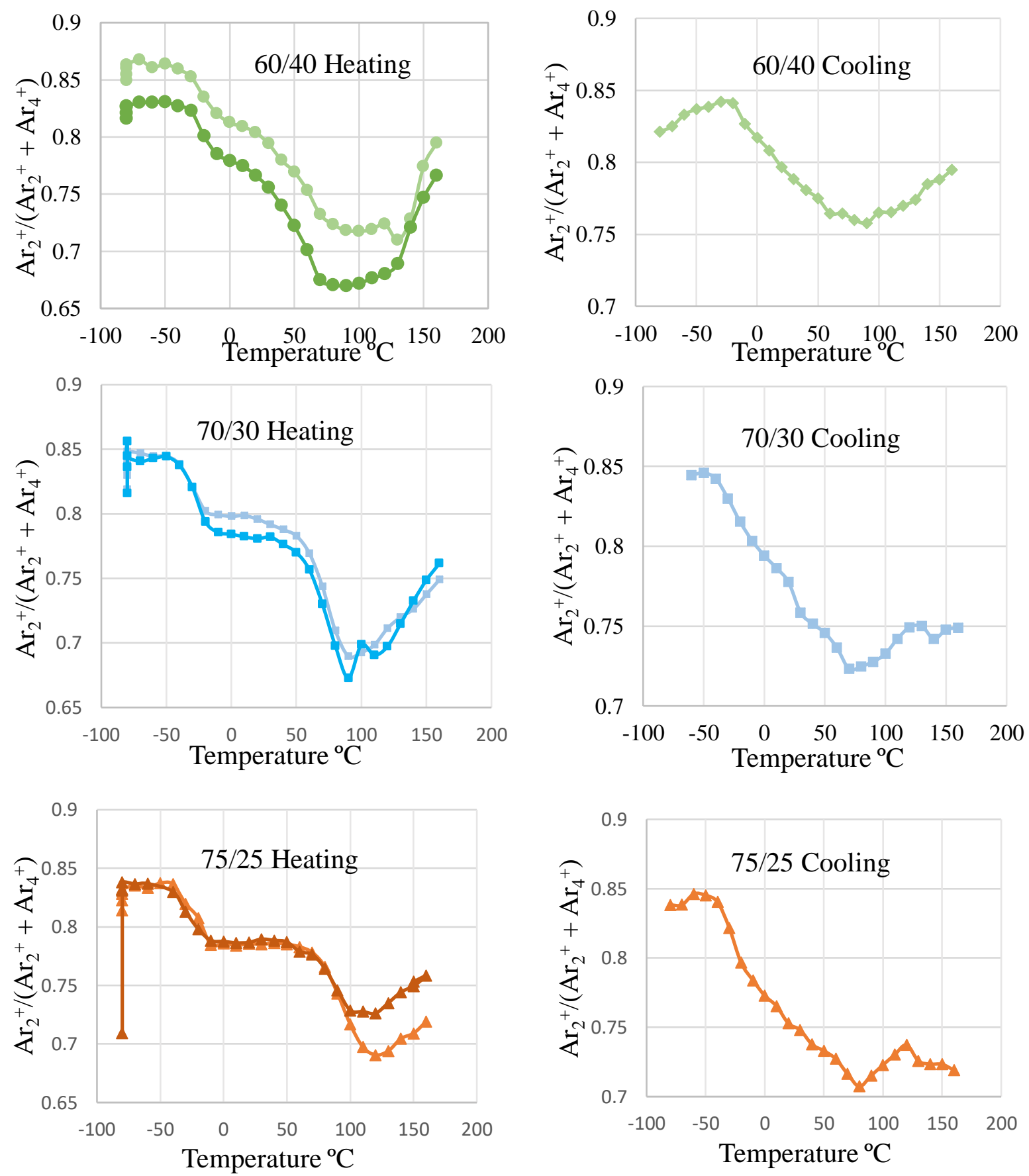

Figure S2 Evolution of the $\mathrm{Ar}_{2}{ }^{+} /\left(\mathrm{Ar}_{2}{ }^{+}+\mathrm{Ar}_{4}{ }^{+}\right)$breaking ratios as a function of temperature upon heating and cooling of $\mathrm{P}(\mathrm{VDF}-\mathrm{ran}$-TrFE) thin films: a) 60/40, b) 70/30, c) 75/25 


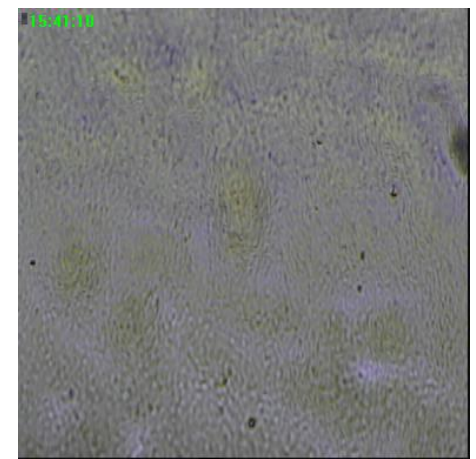

$120^{\circ} \mathrm{C}$

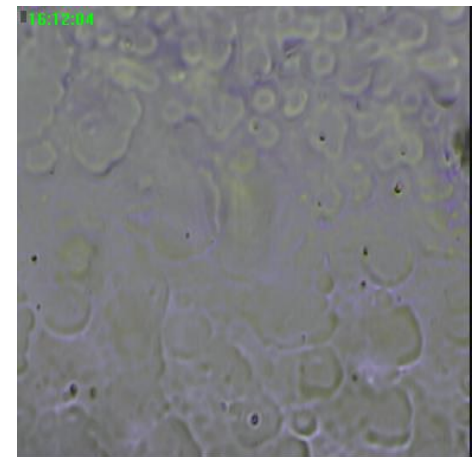

$140^{\circ} \mathrm{C}$ end

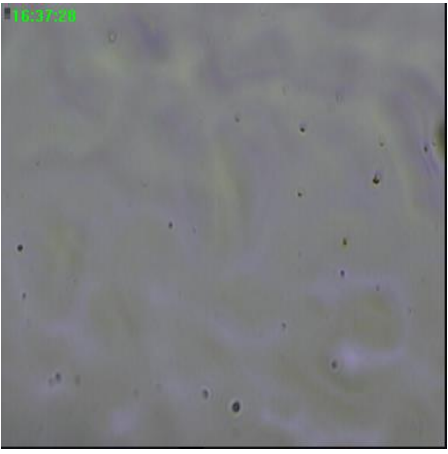

$160^{\circ} \mathrm{C}$ start

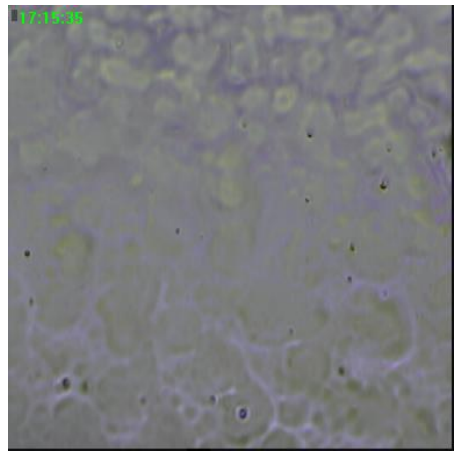

$140^{\circ} \mathrm{C}$ end cooling

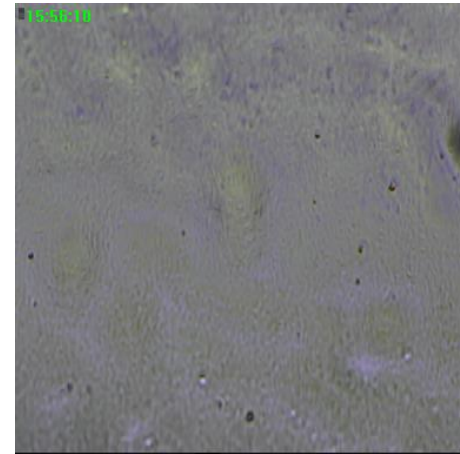

$130^{\circ} \mathrm{C}$ end

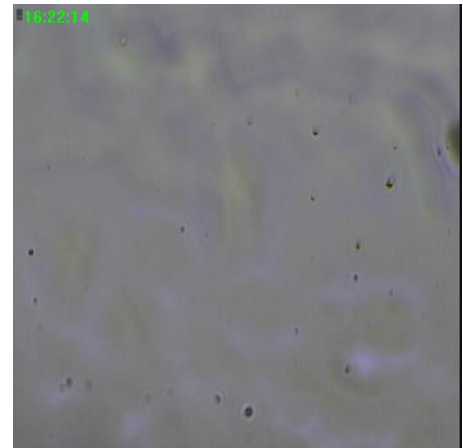

$150^{\circ} \mathrm{C}$ start

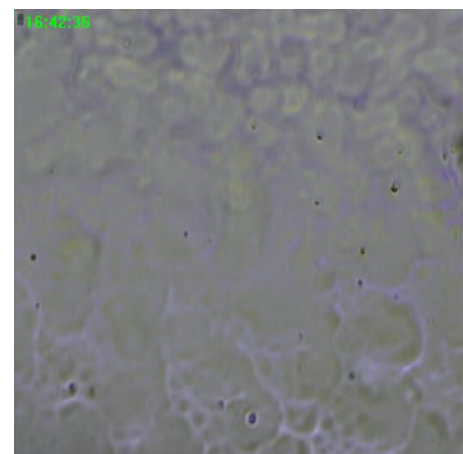

$160^{\circ} \mathrm{C}$ end

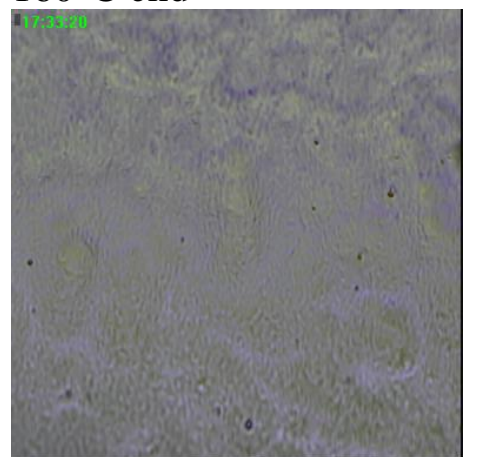

$130^{\circ} \mathrm{C}$ end cooling

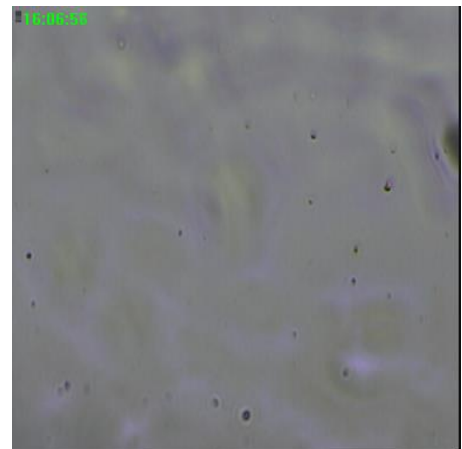

$140^{\circ} \mathrm{C}$ start

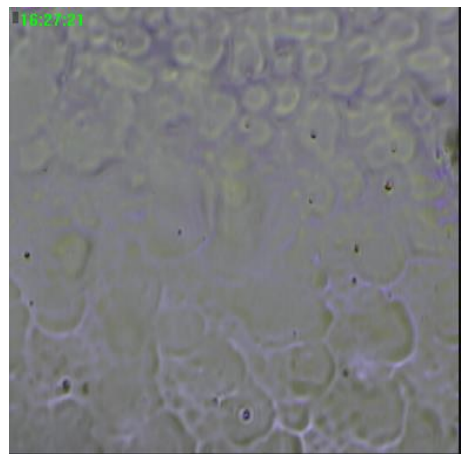

$150^{\circ} \mathrm{C}$ end

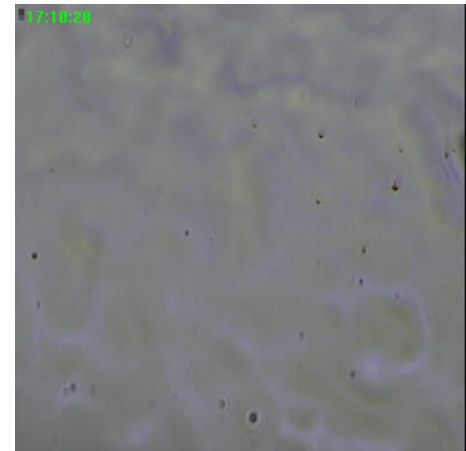

$140^{\circ} \mathrm{C}$ start cooling

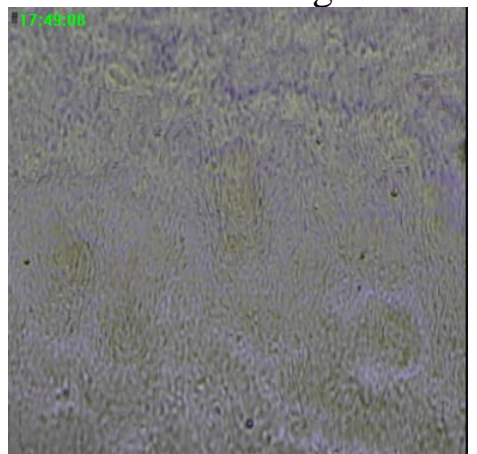

$120^{\circ} \mathrm{C}$ end cooling

Figure S3 Microscopic pictures of the coatings of $\mathrm{P}(\mathrm{VDF}-$ ran-TrFE) 75/25 sample heated up to $160{ }^{\circ} \mathrm{C}$ 
$60 / 40$

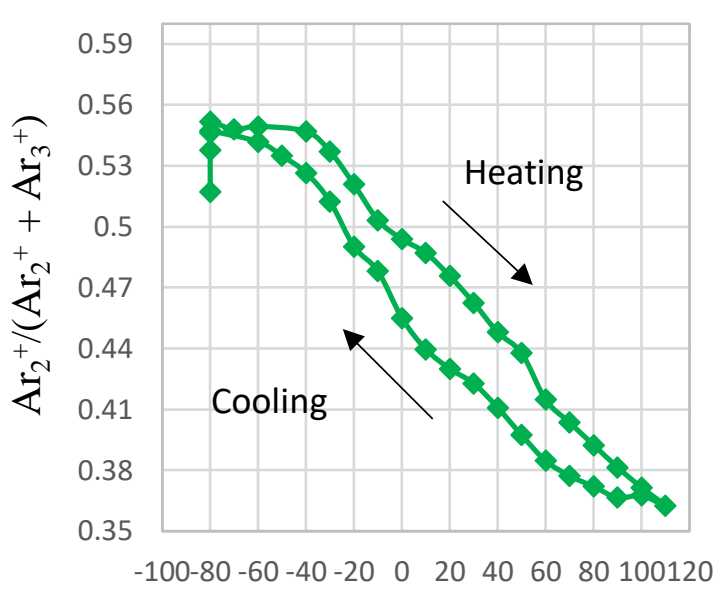

Temperature ${ }^{\circ} \mathrm{C}$
$60 / 40$

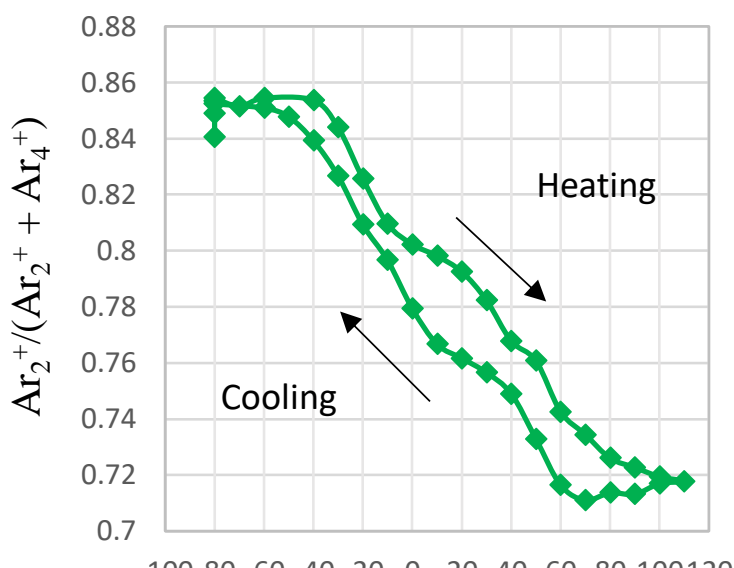

Temperature ${ }^{\circ} \mathrm{C}$

Figure S4 Evolution of the $\mathrm{Ar}_{2}{ }^{+} /\left(\mathrm{Ar}_{2}{ }^{+}+\mathrm{Ar}_{3}{ }^{+}\right)$and $\mathrm{Ar}_{2}{ }^{+} /\left(\mathrm{Ar}_{2}{ }^{+}+\mathrm{Ar}_{4}{ }^{+}\right)$breaking ratios as a function of temperature upon heating to $110^{\circ} \mathrm{C}$ and cooling of $\mathrm{P}(\mathrm{VDF}-\mathrm{ran}$-TrFE) $60 / 40$ sample
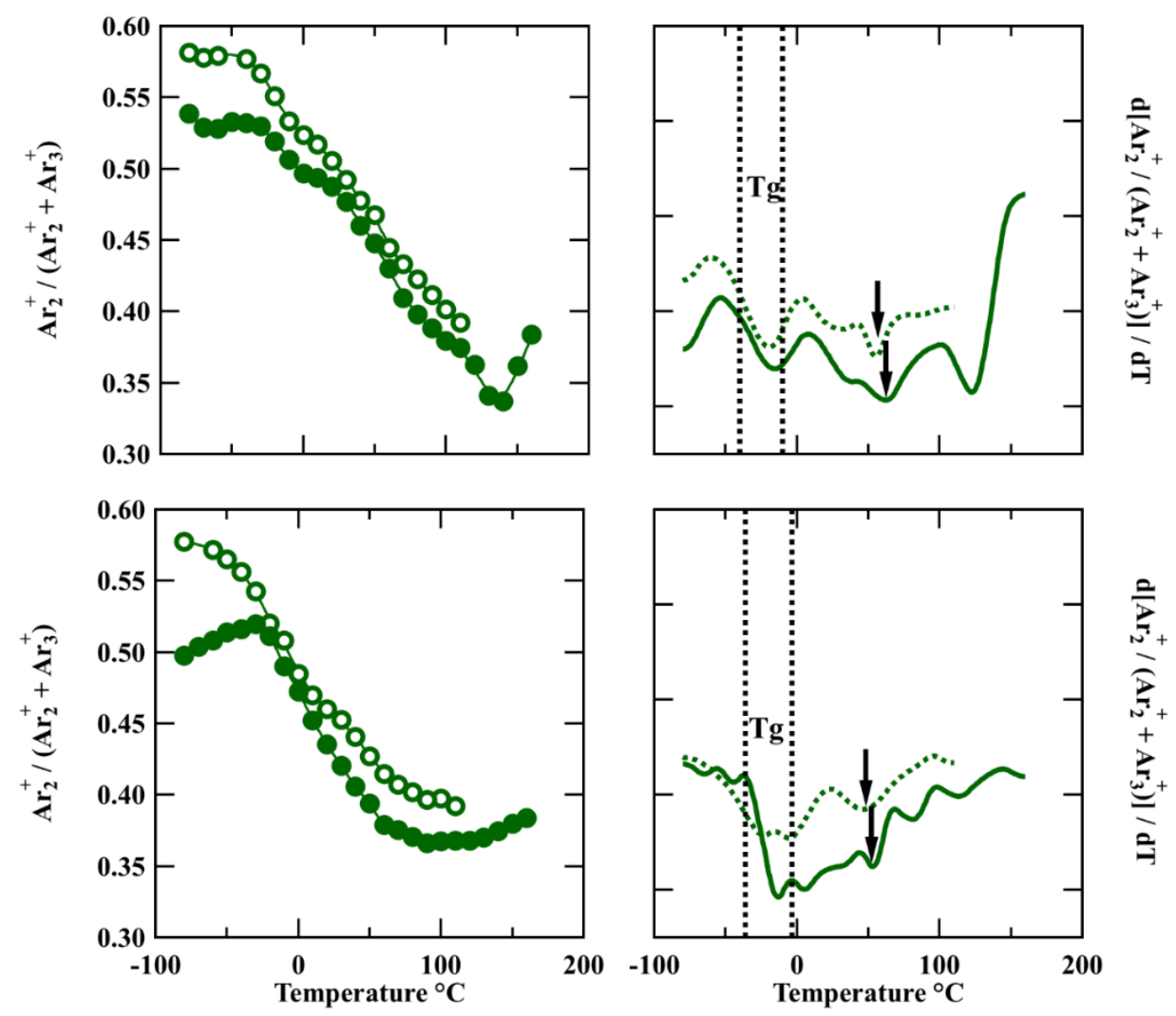

Figure S5 Temperature derivative of the $\mathrm{Ar}_{2}{ }^{+} /\left(\mathrm{Ar}_{2}{ }^{+}+\mathrm{Ar}_{3}{ }^{+}\right)$breaking ratio of $\mathrm{P}(\mathrm{VDF}-\mathrm{ran}$ TrFE) 60/40 sample as a function of temperature upon heating (filled circles are of the sample undertaking melting, open circles for the non-molten one in the ratio graphs; plain lines and dashed lines in the derivatives are for the initial and non-melted sample respectively). Heating is the top row with plots, cooling is the bottom row. 

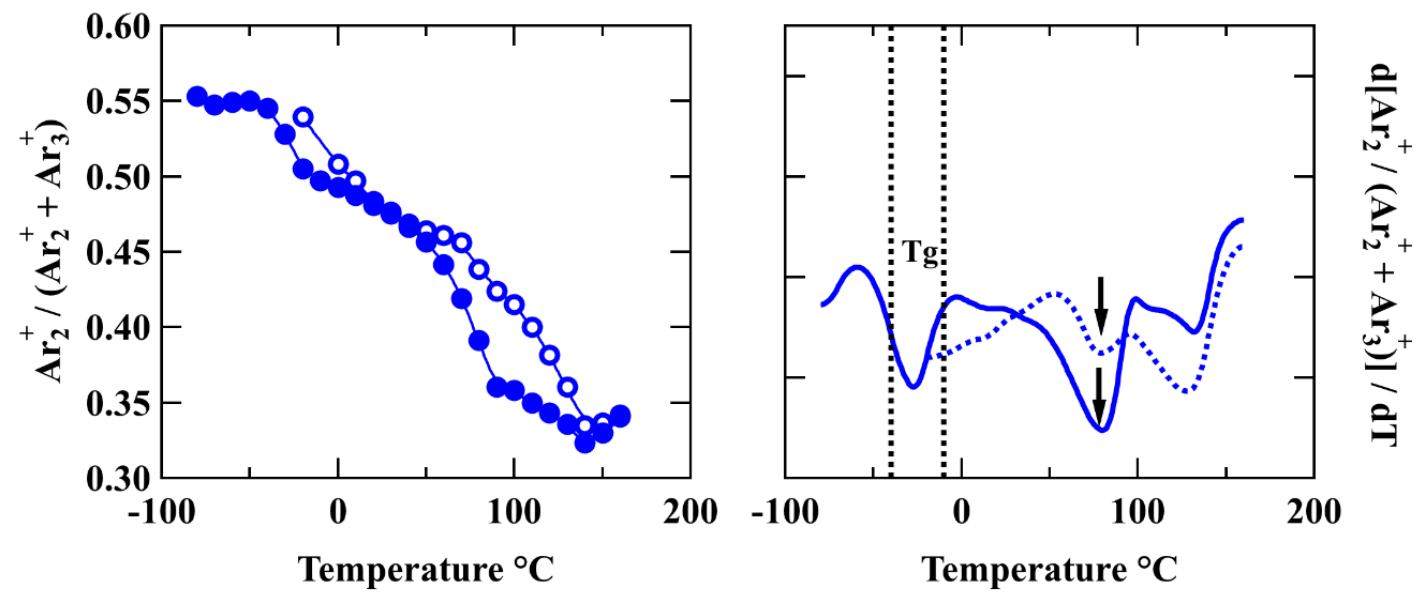

Figure S6 Temperature derivative of the $\mathrm{Ar}_{2}{ }^{+} /\left(\mathrm{Ar}_{2}{ }^{+}+\mathrm{Ar}_{3}{ }^{+}\right)$breaking ratio of $\mathrm{P}(\mathrm{VDF}-$ ran-

TrFE) 70/30 sample as a function of temperature upon heating (filled circles are of the sample undertaking melting, open circles for the sample without erasing the thermal history by melting in the ratio graphs; plain lines and dashed lines in the derivatives are for the initial and non-preheated sample respectively).
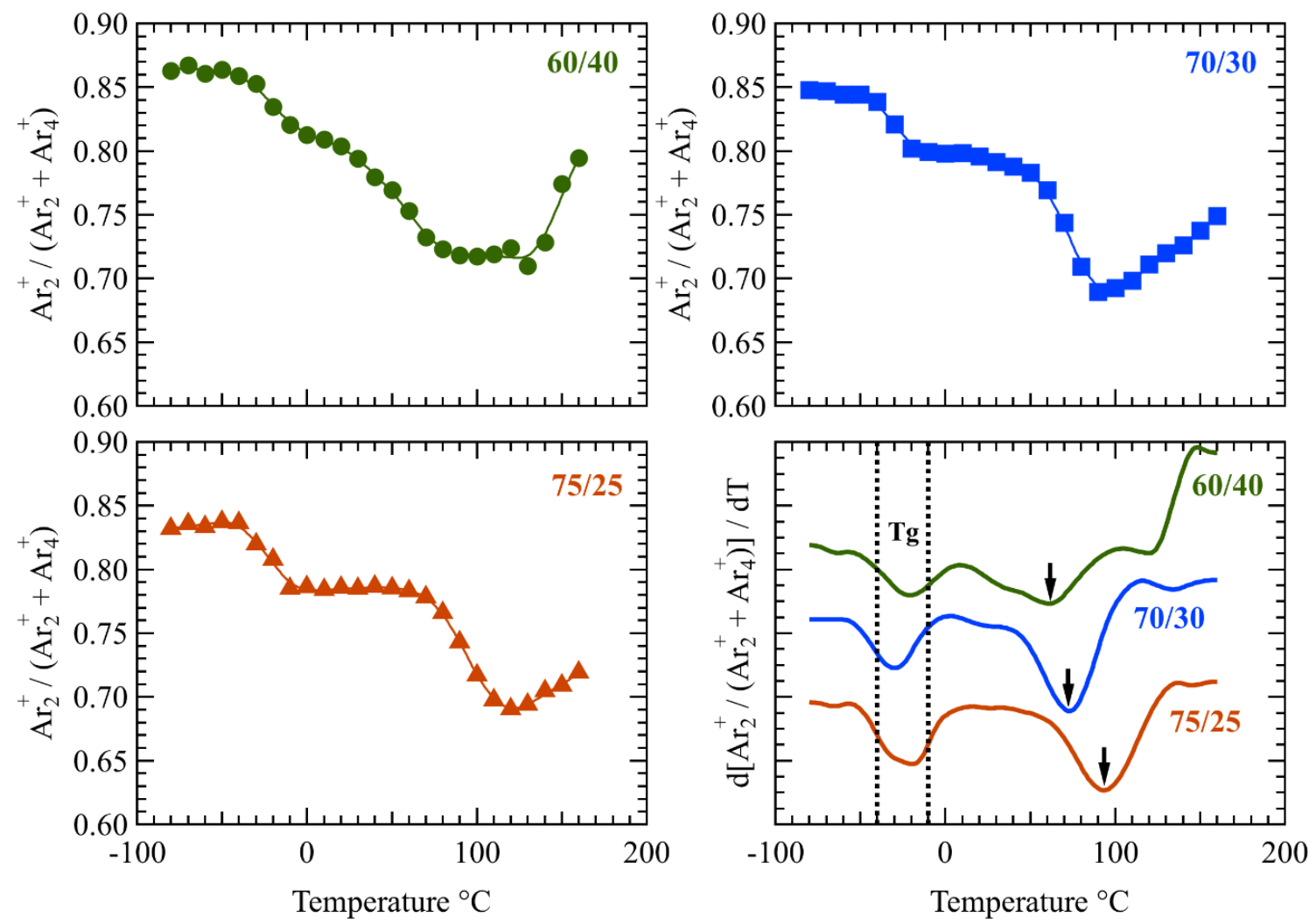

Figure S7 Evolution of the $\mathrm{Ar}_{2}{ }^{+} /\left(\mathrm{Ar}_{2}{ }^{+}+\mathrm{Ar}_{4}{ }^{+}\right)$breaking ratio as a function of temperature upon heating of $\mathrm{P}(\mathrm{VDF}-\mathrm{ran}$-TrFE) thin films 60/40, 70/30, 75/25 and their respective temperature derivatives of the $\mathrm{Ar}_{2}{ }^{+} /\left(\mathrm{Ar}_{2}{ }^{+}+\mathrm{Ar}_{4}{ }^{+}\right)$ratio. 